\title{
INCONSCIENTE Y VOLUNTAD EN LOS TEXTOS INÉDITOS DE ORBE (1926-1931), DE JUAN LARREA
}

De 1926 a 1931 se manifiesta en la obra de Juan Larrea, Orbe, una crisis personal que el autor identifica con la crisis que el mundo occidental está viviendo en esa época ${ }^{1}$. Ciertamente, el libro se escribe como diario espiritual en el que Larrea ahonda en su situación vital, al tiempo que reflexiona sobre la literatura o la depresión económica en la que Europa y América estaban inmersas. En este diario espiritual se reflejan las distintas corrientes de pensamiento que se entrelazan y combaten en estas décadas, convirtiéndose el libro en un importante testimonio intelectual de las incertidumbres y esperanzas del momento y, principalmente, de las tendencias filosóficas que subyacen a determinados postulados vanguardistas. Para comprender la evolución del autor, es necesario analizar el texto original (del que se conserva una copia mecanografiada por César Vallejo), pues las 384 páginas que en el texto de Vallejo cubren este período (de 1926 a 1931) quedan reducidas en la edición de Seix

1 Una exposición de esta crisis en la vida de Larrea la encontramos en David BARY, Poesía y transformación, Planeta, Barcelona, 1976 y en Miguel Nieto, "Introducción”, en Juan Larrea, Versión celeste, Cátedra, Madrid, 1989, pp. 28-33. En adelante, los textos de Orbe incluidos en la edición de Pere Gimferrer (Juan Larrea, Orbe, Seix Barral, Barcelona, 1990) aparecen con la indicación de la página; para los fragmentos inéditos sigo la copia mecanografiada por Vallejo, que se señala como $M$. De las dos copias conocidas, la que se encuentra en los archivos de Larrea (que fueron conservadas por Alejandro Finisterre hasta su muerte) y el mecanoscrito entregado por Larrea a Gerardo Diego, este último ha sido el material consultado para el presente estudio, gracias a la generosidad de Miguel Nieto. 
Barral a las primeras cincuenta y nueve del libro ${ }^{2}$, desdibujando el perfil y las razones de una crisis que, si bien compleja y ambigua, no deja de ser asediada una y otra vez por Larrea en un intento por encontrarle un sentido. Esta crisis supone la destrucción de los pilares sobre los que se sustenta el edificio de la metafísica occidental; nos revela en el pensamiento del autor la presencia de unos fundamentos idealistas y románticos tamizados por la obra de Schopenhauer y Nietzsche.

El establecimiento de estas influencias ayuda a concretar la corriente de pensamiento que conecta el fin de siglo con algunos movimientos de vanguardia. Podemos empezar a establecer una de las líneas fundamentales de la modernidad literaria y su vinculación con el Romanticismo, así como discernir cuáles son los conceptos que se reciben y en qué medida o bajo qué nuevo horizonte de sentido se sitúan. También queda clara en Larrea la modulación vanguardista frente a la sensibilidad finisecular de estirpe schopenhaueriana (aunque ambas beban en la tradición romántica, como se observa en los rasgos que enunciamos): desde una concepción teleológica de la realidad, presente en el idealismo alemán (pero ausente en Schopenhauer, quien niega explícitamente cualquier finalismo en la voluntad), en Larrea hallamos la proyección hacia un futuro utópico (con acentos apocalípticos). Consecuentemente, se descubre una nueva concepción del hombre y una nueva moral (que se separa, por influencia nietzscheana, de la compasión o piedad, que por influjo de Schopenhauer impregna parte de la

2 Si bien la antología recoge textos fundamentales (como "Cuzco", "Publicación" o "Fin de mi poesía"), Gimferrer parece haber hecho la selección con el fin de captar el interés del lector; de ahí que abunden los textos sobre la situación política histórica y la crisis económica (especialmente los análisis sobre Rusia, Alemania o Italia, o sobre el papel de Estados Unidos), detalles de la vida afectiva del autor (textos referidos a su relación con Marguerite Aubry, como "El sexo errante"), peripecias como la salida de las estatuillas de Perú, o anécdotas (como los sueños y premoniciones de las carreras de caballos) que, desgajadas del conjunto parecen revestir un carácter meramente pintoresco o extraño. Ciertamente, los sueños, premoniciones y casualidades (como las que le ayudan a salir de Perú con el tesoro arqueológico) desempeñan una función importante, al revelar (o corroborar, posteriormente) la concepción de la vida como obra de arte, como tejido orgánico en el que todo cumple su función, se encuentra en su sitio y, por tanto, debe ser así. Se observa en la antología la casi completa desaparición de textos metaliterarios y la no inclusión de reflexiones filosóficas fundamentales para entender la crisis y los conceptos que entran en juego. 
sensibilidad finisecular); finalmente, el arte se funde de modo indisoluble con la vida.

Si Francisco José Martín observa en el fin de siglo español (y europeo) "una especie de nebulosa nietzscheano-schopenhaueriana, una suerte de tótum revolútum en el que no siempre era posible establecer las diferencias esenciales que separaban a ambos autores"', en Orbe se manifiestan igualmente diversas influencias (a veces contradictorias), entre las que destacan especialmente Schopenhauer y Nietzsche, si bien el tronco en el que éstas vienen a injertarse es una filosofía idealista. $\mathrm{Al}$ no ser un tratado de filosofía, los conceptos pueden emplearse con acepciones distintas y a veces contrarias (es el caso del término "voluntad"); sin embargo, esta filosofía idealista aclara y torna consecuentes y lógicos ciertos rasgos larreanos que han llevado a algunos a tildar su pensamiento de "delirante"4.

Se encuentran en Orbe de manera continua dos principios fundamentales (polaridad y teleología) que, según Larrea, vertebran toda la realidad desde su nacimiento en un despliegue orgánico. La unidad de un principio al que se otorgan rasgos divinos (la Voluntad cósmica, la Imaginación) se escinde en dos fuerzas cuyo enfrentamiento produce síntesis cada vez más elevadas y complejas. Esta concepción de la realidad remite a la $\mathrm{Na}$ turphilosophie de Schelling y a la tradición filosófica que de éste procede (especialmente, la cosmovisión de Schopenhauer). En el presente artículo se sigue esta línea de pensamiento a partir de los conceptos de Voluntad e Inconsciente (y su final transformación en Imaginación), pues éstos marcan la destrucción del yo individual, punto sobre el que se cimenta la metafísica occidental ${ }^{5}$. No obstante, es imprescindible (en esta filosofía) tener siempre presente la homogeneidad que existe en toda la realidad; ello explica (como no se cansa Larrea de repetir a lo largo del libro) que la crisis personal que atraviesa el autor sea igualmente la crisis de Occidente; de ahí que debamos comenzar con esta conexión, pues la rebelión contra la metafísica occidental y el predominio en ella de nociones como voluntad individual, yo y razón, entran definitivamente en "bancarrota" (por emplear

3 Francisco José Martín, "El horizonte de la desdicha. (El problema del mal y el ideal ascético en Azorín)”, ALE, 12 (1996), p. 181.

${ }^{4}$ Cf. Abellán, "Pensamiento y delirio en Juan Larrea”, LD, 1996, núm. 70 , p. 13.

5 Para otro trabajo habremos de dejar la proyección de este pensamiento hacia el porvenir en las figuras del Nuevo Mundo y del Hombre Nuevo. 
el término larreano) en el período de entreguerras, en la crisis política y económica de estos años que, en opinión de Larrea, reflejan la necesidad de un salto cualitativo basado en una nueva forma de concebir la realidad que deje atrás la pesada carga heredada de épocas pasadas.

CRISIS BIOLÓGICA Y ORGÁNICA: INDIVIDUAL, SOCIAL, UNIVERSAL

Ciertamente, desde el inicio, en la serie de textos titulada "Crisis de existencia”, declara Larrea la vinculación estrecha entre la crisis personal y la de la sociedad en la que se encuentra ( $M$, p. 48):

Esta crisis de existencia no es exclusiva del individuo, sino que toda sociedad organizada, no siendo más que un reflejo de él, una ampliación en tiempo y en espacio, participa de ella como una de sus etapas. Y la humanidad lo mismo. Y según su estado de riqueza nerviosa, ayudada por el índice racial subconsciente, este periodo de pequeña muerte se produce más o menos intensamente y con más o menos detrimento. Y la duración varía con el género de componentes que la constituyen.

La crisis es propia de "toda sociedad organizada", pues se trata de una crisis orgánica ${ }^{6}$, casi biológica, que augura un nuevo nacimiento (no es de extrañar, dada la concepción homogénea de la realidad que tiene Larrea). Se observa ya en el texto la estratificación compleja que la humanidad manifiesta en el pensamiento larreano, como conjunto en el que confluyen organismos inferiores (individuo, sociedad, $\operatorname{raza}^{7}$ ). Larrea interpreta su crisis personal (y, por ende, la crisis occidental) como etapa de crecimiento: en una analogía repetida por él varias veces a lo largo del libro, "cierta especie de caparazón espiritual", como sucede en lo físico en muchos animales, debe ser abandonado para que el desarrollo que está adquiriendo pueda encontrar un espacio más amplio. Este caparazón son los conceptos

${ }^{6}$ Larrea emplea este concepto (“crisis orgánicas”) en Orbe. Cf., por ejemplo, "Voluntad" (M, p. 165).

${ }^{7}$ La existencia de un inconsciente de las razas era reconocida por los principales investigadores de Psicología social, como Gustave Le Bon (cf. S. Freud, Psicología de las masas y análisis del yo, en Obras completas, Editorial Biblioteca Nueva, Madrid, 1981, t. 3, p. 2565). 
en los que hasta ahora el hombre ha sustentado su vida y, de los que, como habitaciones estrechas, ha de despojarse ${ }^{8}$. Pero para ello ha de pasar por una noche oscura, por el sufrimiento de un parto en el que sus cimientos son socavados ("su memoria le olvida, su voluntad le traiciona", "el delirio, la pesadilla son sus únicos compañeros"), experiencia que lo lleva a compararse con Job, Rimbaud, Cristo y Lutero. Es el gran temporal que acompaña el paso de la juventud a la edad madura.

Igualmente, la crisis del mundo occidental es una crisis de crecimiento ( $M$, p. 109), en la que con violento dolor está naciendo un espíritu nuevo, rompiendo los estrechos e insuficientes moldes de la política, la economía o la sociología, tratando de llegar a una "concreción armónica definitiva". En Orbe se observa la crítica a todos los principios en que se basa la civilización europea: el yo, la realidad, la verdad, la moral, el cristianismo, el concepto de espacio y de tiempo, la primacía de la voluntad consciente ${ }^{9}$. En un texto inédito fechado el 29 de marzo de 1931, expresa el autor cómo había obedecido a "la antigua ideología del mundo" en que había nacido, llegando a tomar su vida un derrotero trágico. Por ello ha tenido que vencer los viejos conceptos de su educación en su interior para expulsarlos; sólo así ha podido conocer su mal y curarse, aunque para ello ha debido disgregar su yo. De este modo se congenia el autor con la verdad actual, es decir, con "el modo de ser de la naturaleza de acuerdo con la corriente del mundo en esta hora" y, tras derrotar a los antiguos supervivientes con los que ha debido entablar la guerra, puede entrar de lleno "en la nueva época", la "nueva verdad", viviendo consciente la misma hora que vive el inconsciente humano:

${ }^{8}$ Sobre la necesidad que siente Larrea en esta época de abandonar todas las viejas formas de la civilización europea, cf. la carta a Diego fechada el 10 de enero de 1930, en Juan Larrea, Cartas a Gerardo Diego, eds. E. Cordero de Ciria y J.M. Díaz de Guereñu, Cuadernos Universitarios, San Sebastián, 1986, p. 224.

9 Se trata de una fase "disgregatoria" (cf. Benicio del Pliego, La obra ensayística de Juan Larrea y los fundamentos de la modernidad artística, tesis doctoral, Universidad Autónoma de Madrid, Madrid, 2002, p. 114). Esta crítica radical coincide con la filosofía nietzscheana: "No hay ni «espíritu», ni razón, ni pensamiento, ni conciencia, ni alma, ni voluntad, ni verdad; éstas no son más que ficciones inútiles" (cf. Friedrich Nietzsche, La voluntad del dominio, Aguilar, Buenos Aires, 1947, p. 307). Sin embargo, por su creencia en el Progreso y en una Voluntad Inconsciente, por su filosofía organicista y su teleología, el pensamiento larreano tiene su raíz más clara en el idealismo. 
Veo cómo la educación absurda de mi juventud, todas las fuerzas de los que me han rodeado durante tantos años, fuerzas conscientes e inconscientes, todos los esfuerzos unidos para deformarme y asesinarme a mí que era el porvenir, para deformarme con arreglo a un determinado molde, lejos de haber conseguido su fin, no han hecho quizá sino que mi naturaleza reaccione por revolución, con toda inocencia, con toda insumisión de víctima dócil que a su propia costa y sin hacer daño ni venganza sigue magníficamente su camino, pero sin que nadie pueda detenerla... Pero tantos esfuerzos conjugados para deformarme, tantas intentonas de quebrantamiento de mi voluntad -sin darse cuenta que detrás de esta voluntad estaba la voluntad del mundo-, consiguieron alcanzarme, crear un conflicto, una contradicción entre las ideas recibidas a martillo y la tendencia incontenible de mi destino, conflicto que fue minando mi organismo, hasta transmutarse en un desequilibrio vegetativo, síntoma y válvula de ese pus psíquico segregado por mi naturaleza para arrojar mañana de un golpe y en el momento en que oportunamente se hace consciente, los cuerpos extraños de ideas que me han introducido ( $M$, pp. 209-210).

El trasfondo romántico que constituye la base del pensamiento de Larrea se manifiesta aquí con total claridad. Como se observa en este texto (de carácter rousseauniano), las ideas aprendidas resultan un atentado contra la Naturaleza, un acto violento de deformación del espíritu del niño, porque se superponen al crecimiento espontáneo y libre (orgánico) de las potencialidades que la Naturaleza ha dejado en él. Las ideas cristianas son exteriores, extrañas a la voluntad del mundo. Enemigas de la tendencia de la Naturaleza, actúan en el caso biográfico de Larrea (según su interpretación) igual que en la Historia: son necesarias porque han difundido algunos conceptos verdaderos (especialmente la idea de catolicidad) y porque, aunque frenan el progreso, terminan por provocar la reacción que llevará al avance de la Humanidad. Observamos, pues, la teleología que preside la concepción de la Historia en Larrea: la voluntad del mundo dirige de modo inexorable a los seres humanos hacia una meta tan necesaria como oculta para la consciencia. Con frecuencia, este designio parece oculto, pues trabaja desde su contrario: fortaleciendo la opresión acaba por engendrar la revolución que acaba con aquélla. Si, en la vida de Larrea, estas ideas han tratado de deformar su espíritu y han forzado la rebelión contra la moral católico-burguesa 
y contra la idea del yo, también en la Historia se vive el instante en el que las instituciones del pasado, que han ido aumentando su poder, se encuentran fosilizadas y necesitan dar paso a un mundo nuevo.

\section{DESAGREGACIÓN DEL INDIVIDUO}

La superación de la crisis se encuentra ligada a la superación de la noción del yo, o mejor, la ampliación de este concepto, que viene a integrarse en una unidad superior, la del yo colectivo; para ello es necesario que el yo se desintegre. En esta desintegración se manifestarán fuerzas anónimas o inconscientes que acabarán por desterrar la noción de yo individual tal y como existe. Cumple una función crucial el descubrimiento de una voluntad diversa a la voluntad individual, como se observa ya en el texto anterior. La primera afirmación sobre el yo que se halla en Orbe niega la existencia de la personalidad, negando la unidad del yo para disolverlo en la multiplicidad:

Descubro que mi personalidad no existe, que no es más que un mero producto cerebral adquirido por la costumbre y por la aportación de extraños. Una pura idea, encrucijada de un giro gramatical, costumbre de decir yo para expresar lo que se escapa a los sentidos corporales, de la idea del tiempo y de la del espacio. Pero comprendo que no soy más que una sucesión de pequeños tiempos que se hacen materia... $(M, \text { p. } 15)^{10}$.

El yo se descubre como una ficción impuesta (igual que las categorías de tiempo y espacio, que se revelan falsas), bajo la que subyace un cambio continuo que no puede reducirse a la unidad. Esta concepción heracliteana (presente en Schopen-

10 Esta crítica del yo como producto de la costumbre y la gramática, vuelve a relacionar a Larrea con la demolición de la metafísica occidental nietzscheana. A partir de una intuición heracliteana del devenir ("no soy más que una sucesión de pequeños tiempos que se hacen materia") la realidad se torna en un fluir en el que nada permanente existe. Observamos esta crítica del yo en La voluntad del dominio: "«se piensa: luego hay una cosa que piensa»: a esto se reducía la argumentación de Descartes. Pero esto es dar ya por verdadero «a priori», nuestra creencia en la idea de substancia. Decir que, cuando se piensa, es preciso que haya una cosa que piensa es simplemente la formulación de un hábito gramatical que a la acción atribuye un actor" (p. 309). 
hauer y Nietzsche) produce, como afirmó éste en La filosofía en la época trágica de los griegos, el mismo efecto que si vacilara el suelo bajo los pies, pues sin los conceptos que dan estabilidad al mundo, la persona no tiene asidero.

El yo que ha de desintegrarse para renacer en el yo colectivo se vincula al "yo personal", a la consciencia y a la voluntad consciente. Precisamente el descubrimiento de una voluntad inconsciente (llamada voluntad del mundo, voluntad cósmica), que de modo inexorable va conduciendo los acontecimientos (aun a pesar de la voluntad consciente), derrumbará los escasos apoyos que apuntalaban al yo personal (ni siquiera queda la libertad individual, pues el hombre es movido por fuerzas que no controla). Esto sólo será posible tras una fase de "exasperación" de la voluntad consciente, que ha de adquirir un poder absoluto a fin de que el escritor perciba dolorosamente el engaño a que ha sido sometido ${ }^{11}$. De nuevo encontramos el principio acción-reacción que dirige (de manera a veces oscura) los destinos del hombre y de la Historia. De hecho, esta fase de "exasperación de la voluntad consciente" no sólo se revela en la vida de Larrea, sino que ha dominado los últimos años la política mundial (véase la Gran Guerra).

La personalidad es el fruto de unas operaciones complejas que acaban por formar lo que Larrea denomina "la colocación" del yo. En estas operaciones la especie da la materia primera, pero "la raza con sus índices de selección y la educación sobre todo, el medio ambiente ejercen una influencia decisiva" ( $M$, p. 67). El yo es producto de unas actividades exteriores al indi-

11 Este engaño continuo en el que cae el hombre remite a la filosofía de Schopenhauer. Se observa, así, en el texto fechado el 13 de noviembre de 1929, en el que expresa el paso de un período de decaimiento a otro de sobreexcitación ( $M$, p. 64). Cf. $M$, p. 88: "En el fondo la vida de la humanidad se reduce a lanzarse a la conquista de la realidad y cuando parece que su ilusión va a realizarse, darse cuenta de que ha sido engañada por ella misma, es decir, por su inconsciente. Y vuelta a empezar en sucesivos engaños sin desmayar nunca. -Me has engañado. -Me has engañado. -Me has engañado. -Me has engañado". Como afirma A. SchopenHauer, "infatigablemente, vamos de deseo en deseo y, aun cuando la satisfacción alcanzada no nos satisfaga tanto como prometía, sino que la mayoría de las veces pronto se presente como un vergonzoso error, no nos damos cuenta de que nos las habemos con el tonel de las Danaides; por el contrario, corremos siempre hacia un nuevo deseo" (El mundo como voluntad y representación, F.C.E.-Círculo de Lectores, Madrid-Barcelona, 2000, p. 415). 
viduo, sobre las que él poco puede ${ }^{12}$, intersección de herencia y medio.

La cosmovisión de Larrea, heredera indirecta del panteísmo idealista (de la Naturphilosophie de Schelling), continuamente presenta cualquier fenómeno dividido en dos opuestos cuya armonía ha de ser realizada (si bien, al negar una y otra vez la existencia de un Absoluto, esta unidad recae nuevamente en la división -imagen que no deja de recordar el eterno retorno nietzscheano). Esta polaridad (o lucha) se va a manifestar desde el nivel microscópico al social, de la conformación de la psique, a las guerras entre coaliciones de países, o pugnas ideológicas o políticas en una nación. Así, el hombre "perfecta y simétricamente situado es aquel que presenta su yo, su centro de gravedad, justamente en la línea divisoria de la realidad exterior y de su realidad interior" ( $M$, p. 117). Si la realidad es independiente de la voluntad del hombre, la realidad interior (denominada en otros textos "irrealidad") o mundo psicológico subjetivo es independiente de la voluntad de ese mundo exterior. El hombre ha de buscar hallarse en el fiel de esta balanza. El descubrimiento del autor en estos años de crisis es la existencia de una voluntad a la que tanto la voluntad exterior como la subjetiva obedecen.

Interpretando la obra Más allá del principio del placer, en el fragmento "Trinidad", Larrea entiende el yo como un móvil puesto en movimiento por dos fuerzas antagónicas: el inconsciente que obedece al instinto de conservación y el inconsciente que rige el instinto de la especie. Esas fuerzas "semi-contrarias que en el fondo abstracto, sin existencia, no constituyen sino una sola, han empezado a ser dos en el momento en que han entrado en el tiempo y en él a vivir". Nuevamente encontramos un esquema idealista: una unidad inicial que se subdivide en el mundo caído de la temporalidad en dos fuerzas que, sin dejar de ser realmente una, se oponen, originando el movimiento. El yo pierde su libertad y su individualidad, mera superficie llevada por fuerzas que no controla. Si toma partido (mediante la voluntad consciente) por una de estas fuerzas inconscientes, como habitualmente sucede, se parcializa cayendo en conflictos irresolubles.

12 Se observa, igualmente, el lenguaje darwinista y el peso del medio, que prefiguran una visión determinista (que tratará de unificar mecanicismo y organicismo). 
En Larrea la atracción por la dualidad es tal que el esquema freudiano más complejo (forjado a partir de Más allá del principio del placer ${ }^{13}$ y consolidado en 1921 en $\mathrm{El}$ "yo" y el "ello") es continuamente sustituido por la oposición entre consciente e inconsciente, según se observa en "Esquema del hombre psíquico":

Se ve que el Ser se halla dividido en dos trozos que debieran estar unidos, lo mismo que el cosmos. "Consciente exterior" es la naturaleza perceptible por los sentidos humanos, de la cual somos medios producto. "Inconsciente interior" son las fuerzas que actúan de otro modo y que no son perceptibles por los sentidos exteriores ( $M$, p. 135).

La división se prolonga entre pensamiento consciente/ pensamiento inconsciente, entre memoria consciente/memoria inconsciente. La armonía entre consciente e inconsciente es necesaria para la unidad del hombre ${ }^{14}$. Esta armonía se describe con frecuencia en términos mecanicistas: en los momentos de crisis "el engranaje del consciente con el inconsciente y de las diversas ruedecillas de cada uno de ellos entre sí pierden el contacto normal y empiezan a organizarse del modo más en apariencia absurdo y complicado" (p. 54). El yo es el núcleo alrededor del cual giran las "moléculas psíquicas" (obsérvese la pérdida de unidad), debajo del cual se abre el abismo del inconsciente. Al romperse, en el momento de crisis, la unidad entre consciente e inconsciente, se produce la desagregación, tomando conciencia el creador de la multiplicidad de fuerzas independientes que se esconden en su interior, de la infinitud de pseudo-individualizaciones psíquicas que pueden nacer dentro: todo aquello capaz de individuación posee una voluntad que se alza contra su enemigo. Pero tras esta multiplicidad descubre Larrea una fuerza voluntaria inconsciente más poderosa "de la que el hombre es sólo efecto" ( $M$, p. 166).

Durante la crisis en la que se debate el escritor se produce esta desagregación de la personalidad (proceso que interpreta inicialmente como una amenaza). Larrea lee los aconteci-

13 Esta obra es esencial para entender la oposición (nuevamente dual) entre placer y dolor en Orbe.

14 Cf. $M$, p. 67: "Es preciso que consciente y subconsciente adopten un ángulo estable, una ecuación de una determinada armonía para que la sensación de una unidad sea factible". 
mientos que se desarrollan en su interior a partir de la teoría freudiana expuesta en $E l$ "yo" y el "ello". El desarrollo exagerado del consciente, con el imperio de la voluntad personal, es síntoma de la disgregación, comenzando a sentir la presencia de varias personas psíquicas: el yo (es decir, el consciente y voluntario) y el resto tenebroso, que divide en "tú" (así parece denominar al "ideal de yo" freudiano) y "él" (los apetitos, como interpreta al "ello"); si bien, afirma, éstas no existen como tales. En su vida particular se ha repetido el fenómeno propio de la civilización occidental (la tiranía del consciente), pero la reacción violenta que ha producido en el subconsciente ha motivado la percepción "de la no existencia de ese yo voluntario, de todo lo que significa de atentado contra la vida, de su inconsistencia fantasmal de ídolo engañoso" ( $M$, p. 198). La pérdida de unidad y descomposición del yo motivada por el imperio de la razón, la consciencia y la voluntad (que hacen que las otras fuerzas se retiren y hagan sentir su poder desde lo oscuro-reprimido) fuerzan una reacción que lleva a un equilibrio de todas las dimensiones que componen el yo. El equilibrio, la armonía (para la cual la voluntad debe devolver cuanto ha usurpado) conduce nuevamente a la unidad.

Oscila Larrea, pues, a lo largo del libro entre la falta de unidad del yo y la unidad del mismo ("el yo es uno e indivisible", "la personalidad psíquica es una e indivisible"), pues el autor va buscando pequeñas síntesis entre los múltiples elementos que percibe en su interior y la aspiración a la armonía necesaria. Finalmente encuentra la superación de esta dicotomía entre unidad y pluralidad en la concepción de un Yo colectivo, por lo que afirma en este mismo texto que "se vuelve a ser uno y en el yo se percibe la gravitación esencial de todos los componentes del universo". El consciente no es más que un peldaño (la era filosófica, la era consciente absoluta -éste sería su correlato en la civilización europea) cuyo derrumbe muestra el objetivo al que tiende el hombre, "a la unidad natural de la relatividad universal". Se aproxima un hombre nuevo, un "ser semi-consciente". Este hombre nuevo, transfigurado, es un hombre sano, en el que existe la armonía entre consciente e inconsciente, una vez superada la enfermedad colectiva que pone su fe en la consciencia $^{15}$. En este Yo universal el yo personal no es nada, sino

15 Cf. $M$, p. 203: "En el estado inferiorizado y enfermizo de dislocación de la gravedad psíquica, el yo deposita toda su enorme confianza en el cons- 
un conjunto de elementos, como afirma en un texto fechado el 24 de octubre de 1931 (es decir, tras su viaje a Perú y su renacimiento):

El que el yo pueda morir sin que muera el cuerpo en que se asienta, significa que la unidad corpórea y la unidad psíquica no coinciden. Son como dos circunferencias con centro distinto y de diferente diámetro. Y aún más, que la unidad no existe. El yo es determinado por un conjunto de elementos psíquicos, psicológicos, biológicos, etc., diferentes acarreos $\left(M\right.$, pp. 322-323) ${ }^{16}$.

\section{INCONSCIENTE}

Podemos afirmar que el desfondamiento que se produce en la idea del yo sigue una dirección descendente y otra ascendente. $\mathrm{Al}$ abrirse el fondo del inconsciente, el hombre descubre toda la escala que lo lleva a estar en contacto con las formas biológicas primitivas y la organización de la propia materia. Al comprobar la tensión evolutiva que lo lanza a un desarrollo aún mayor, se le manifiesta cómo no es más que un momento que ha de llevar a un yo superior, siendo su forma actual un instrumento cuya finalidad desconoce. Pero ambas direcciones confluyen en una visión monista de la realidad según la cual el ser se desarrolla armónicamente alcanzando estados superiores en su evolución ${ }^{17}$, desde el elemento más simple al más complejo, del átomo al yo universal. En esta visión homogénea de la realidad, que responde al despliegue bipolar de un mismo principio (cuya lucha produce momentos de síntesis), no habría ninguna diferencia en los distintos instantes o peldaños de esta escala: el hombre-individuo

ciente y su desconfianza en el inconsciente. En el caso de falta de desarrollo psíquico, por el contrario, toda la confianza habita en el inconsciente y la desconfianza en el consciente. En el caso armónico de la salud la fe ilumina y cubre por igual todo el campo de la entidad psíquica".

16 "No hay que olvidar que el yo personal es en el fondo un yo plural, constituido por la concurrencia ordenada de tantos microorganismos" (J. Larrea, Orbe, ed. cit., pp. 53-54).

17 A esta descomposición del yo llega también Larrea a partir de la noción de inmortalidad: la sensación de inmortalidad pertenece a cada una de las células que componen el organismo humano, "verdaderas unidades tan unidades como hombre, aunque menos complejas, naciendo, reproduciéndose, sufriendo y muriendo como él” ( $M$, pp. 186-187). 
no es una realidad separada, distinta, sino un momento dentro de un continuum.

Este proceso de desfondamiento del yo afecta las facultades principales del hombre: a partir del subconsciente personal entrevemos el subconsciente universal, tras la voluntad consciente descubrimos la voluntad (inconsciente) universal. En todo caso, la consciencia del yo, es decir, la existencia de un individuo, un ser como un todo independiente, es "un producto cerebral falso, sin realidad verdadera" $(M$, p. 85). La vida se torna un torrente continuo sin divisiones, en una intuición heracliteana del devenir próxima a la nietzscheana.

Frente a la glorificación de la razón (responsable de la crisis occidental), en Orbe asistimos a una reivindicación del inconsciente que, alejado de toda construcción artificial, conecta al hombre con la fuerza originaria y, en este sentido, forjadora del porvenir. En efecto, propugna cómo en el inconsciente individual se manifiesta una fuerza instintiva que le hace escoger lo mejor; sin embargo, el cerebro suele impedir esta elección instintiva, cuando no es anulada por la constitución imperfecta del individuo. Por tanto, lo inconsciente proyecta al hombre (sin que éste intervenga directamente) a un fin verdadero; la intervención de la consciencia y la personalidad perjudica este despliegue de lo inconsciente. Intención subconsciente e intención consciente son las dos fuerzas que velan por el recto caminar del hombre; la intención subconsciente "cuando no es desproporcionada es de una necesidad dinámica total” ( $M$, p. 127), pues no sólo "engendra el movimiento, sino que llegado a este punto lo regula y lo dirige" ( $i d$.$) . Lo inconsciente, en el escalón$ más oscuro del ser, engendra el movimiento (esta idea une aquí a Larrea con la concepción idealista de Eduard von Hartmann, continuador de Schopenhauer). La consciencia llevaría al hombre al absurdo y al extravío; por ello, la intención subconsciente ha de velar por la recta dirección del hombre. Encontramos, según vemos, una idea defendida por Schopenhauer y profundizada de manera más sistemática por Hartmann: el movimiento comienza con una fuerza inconsciente, carente por completo de conocimiento ${ }^{18}$. Mientras actúa inconscientemente, obra de manera infalible, segura e inflexible. La consciencia, sin embargo, introduce la vacilación y el error. Empero, dado que en Schopenhauer la voluntad es simple voluntad de sí, de conserva-

18 Cf. A. Schopenhauer, op. cit., p. 240. 
ción, ésta (considerada negativamente, en tanto fuente de dolor e ilusión) ha de ser anulada por la razón. En Larrea, como veremos, la potencia originaria sufre una transvaloración positiva.

Teniendo presente las ideas expuestas por Freud en Más allá del principio del placer, Larrea halla en la propia naturaleza unas fuerzas acción-reacción que funcionan como en la sociedad y, al mismo tiempo, son las células constitutivas del hombre, tendencias rudimentarias del individuo en perpetuo desequilibrio. Como se puede observar en el texto de Orbe, estas fuerzas son los principios sustentadores de todo lo existente, desde las formas más simples (la célula) hasta las más complejas (sociedades humanas). Hay una homogeneidad en todo lo existente que, a partir de determinados principios idénticos, alcanza una síntesis cada vez más compleja. Encontramos, de este modo, la sentencia hermética de la Tabula Smaragdina: "Lo que está más abajo es como lo que está arriba y lo que está arriba es como lo que está abajo". El hombre como individuo queda disuelto, ya que, por una parte, no es sino una simple formación de los principios que rigen todo el universo; por otra parte, el hombre está llamado a constituir una entidad pluri-individual, un ser superior a la mera persona (el Yo colectivo). De este modo, vuelve a aparecer la vida como tensión entre dos fuerzas opuestas y desequilibradas. Sin embargo, leyendo con atención el texto, se encontrará cómo su visión es monista, pues siempre es un principio que se despliega, se desdobla o se fractura (en este caso las células de diferencia son representaciones de una tendencia reprimida de las células de igualdad; el origen es siempre la identidad):

El hombre, manifestación, como todo cuanto existe, de un desequilibrio de fuerzas extrañas a él presenta un campo de batalla mucho más vasto que los demás animales. Cada una de sus células constitutivas obedece a ese desequilibrio químico. Organizadas en entidad se dividen en células de igualdad, repetidoras, y células de diferencia, transformadoras. Estas últimas no son, desde luego, sino las representaciones concentradas de una tendencia reprimida de las primeras. Ha tenido así que suceder para llegar a formar una entidad colectiva. Es el caso de organización de las abejas y de las termitas, que representan la tentativa no lograda de formar una entidad pluri-individual.

Pero volviendo sobre las reflexiones anteriores, el movimiento de la vida podría quizá definirse como: la manifestación de la acción y reacción de dos energías desequilibradas sobre un móvil 
perteneciente a un medio también de origen dualista y con el cual se halla en equilibrio ( $M$, pp. 139-140).

La concepción es, en estos textos, claramente organicista (podríamos decir incluso "biológica", siendo así una bio-ideo$\left.\log ^{1} a^{19}\right)$. La organización de la propia materia se basa en estos principios, el origen de la vida procede del conflicto entre ellos $^{20}$, y la evolución de la Naturaleza consiste en el conflicto entre estas dos fuerzas. Las sociedades complejas son el desenvolvimiento y la síntesis de este principio contenido ya in nuce en el movimiento inicial ${ }^{21}$.

Retoma Larrea algunos de los principios freudianos, pero adaptándolos a su cosmovisión. Larrea imagina el origen de la vida como fruto del instinto de repetición que influye sobre lo inanimado para producir el estado anterior viviente ${ }^{22}$. Pero, según Freud, "el ser animado elemental no habría querido transformarse desde su principio y habría repetido siempre, bajo condiciones idénticas, un solo camino vital", ya que la meta de toda vida es la muerte y lo inanimado era antes de lo animado (ibid., p. 2526). Por lo tanto, el primer instinto para Freud es vol-

${ }^{19}$ Sobre este término, que se distingue, por tanto, de las simples ideologías (y su proximidad al nacionalsocialismo), cf. Dalmacio Negro, El mito del hombre nuevo, Ediciones Encuentro, Madrid, 2009, p. 248.

${ }^{20}$ Cf. El "yo" y el "ello", en S. Freud, op. cit., p. 2717 (donde evoca Más allá del principio del placer): "A su vez, la vida sería un combate y una transacción entre ambas tendencias. La cuestión del origen de la vida sería, pues, de naturaleza cosmológica, y la referente al objeto y fin de la vida recibirá una respuesta dualista. A cada una de estas dos clases de instintos se hallaría subordinado un proceso fisiológico especial (creación y destrucción), y en cada fragmento de sustancia viva actuarían, si bien en proporción distinta, instintos de las dos clases, debiendo así existir una sustancia que constituiría la representación principal del Eros".

${ }_{21}$ Recuerda esta concepción la expuesta por Nietzsche (La filosofía en la época trágica de los griegos, Valdemar, Madrid, 2001, p. 60) en su estudio del pensamiento de Heráclito (a quien compara en varios de sus principios filosóficos con Schopenhauer): "Se necesita poseer una fortaleza extraordinaria para transformar este hecho en su contrario, esto es, en un sentimiento de lo sublime, de asombro feliz. Esto logró Heráclito al observar el proceso vital del nacimiento y la muerte de los seres y concebirlo como una forma de polaridad, como la escisión de una fuerza dividida en dos actividades cualitativamente diversas, aunque opuestas, tendentes asimismo a una reunificación. Toda cualidad se escinde sin cesar consigo misma y divide en sus contrarias: pero las cualidades contrarias tienden constantemente a reunificarse".

${ }^{22}$ S. FreUd, op. cit., p. 2525. 
ver a lo inanimado; los cambios deben atribuirse a influencias exteriores, porque "todos los instintos orgánicos son conservadores e históricamente adquiridos, y tienden a una regresión o a una reconstrucción de lo pasado" $(i d$.). Los instintos hacia la vida son los instintos sexuales (que, para Freud, son igualmente conservadores, pues reproducen anteriores estados de la sustancia animada): sólo a ellos se les puede atribuir un impulso interno hacia el progreso y hacia un desarrollo más elevado. Para Larrea, vida y muerte, organización y desorganización son simultáneas en el espacio: "Por más que dividamos y subdividamos, en todo seguiremos encontrando siempre la misma dualidad transformadora". Los dos instintos son necesarios para la vida; uno sin su opuesto causaría la desaparición del individuo:

Quizá lo que se pudiera afirmar es que los primeros tienden a una vida (futura) más compleja y los segundos a una vida (anterior) más elemental. Pero la actual vida humana, como toda otra vida, solo es posible por la regulación de ambos, por su relativo equilibrio a fuerza de concesiones mutuas.

Mientras Freud rechaza la existencia de un instinto de perfeccionamiento en el hombre, que cuidaría de su desarrollo hasta llegar al superhombre (ibid., p. 2528), Larrea va a defender precisamente este impulso inconsciente hacia un estado superior de lo humano. Se trata de una fuerza orgánica que en su proyección o desenvolvimiento (mediante la tensión de fuerzas opuestas en las que se manifiesta) va engendrando formas más complejas ${ }^{23}$. La dualidad en que se despliega lo Uno se encuentra en toda la Naturaleza y la Sociedad, de la forma de vida menor a la superior, y esta dualidad o lucha produce síntesis efímeras que se integran en una vida más compleja y perfecta. Se descubre así la raíz idealista del pensamiento larreano, en el que vienen a injertarse otras fuentes (en este caso freudiana). Estas fuentes secundarias son abandonadas en aquellos ámbitos en los que Larrea puede presentir su contradicción con su pensamiento idealista; permanecen en cuanto lo ayudan a profundizar en determinados ámbitos de lo real y no percibe contradicción.

${ }^{23}$ Reconocemos aquí el esquema de Jacob Boehme que va a atravesar la filosofía alemana desde Schelling a Schopenhauer. 


\section{INCONSGIENTE COLEGTIVO Y DESTINO}

La base de esta visión se encuentra en el concepto de inconsciente, en el que no es Freud la única (ni quizá la principal) influencia sobre Larrea. De hecho, en Larrea la afirmación de la existencia de un inconsciente universal (que recibe a veces el nombre de colectivo o genérico), es una creencia más firme que la de un inconsciente individual ${ }^{24}$. Este inconsciente general se despliega en inconscientes parciales. El poeta es el medio del que se sirve "el complejo inconsciente universal para ir elaborando una consciencia y un destino" ( $M$, p. 32), creando una potencialidad de energía inconsciente que se encarna en otro poeta. Lo inconsciente se concibe como un depósito de fuerzas que trasciende al individuo e impulsa el devenir, tomando cuerpo en diferentes hombres (este "encarnarse" es término teológico que se aplica a esta nueva religión secular). A él pertenecen imágenes, símbolos, valores (por ejemplo el anhelo de justicia, que pertenece al "inconsciente colectivo universal" 25 ). En el inconsciente colectivo hay, al igual que en los grupos sociales, estratos, desarrollos que progresan de lo particular a lo universal. De este modo, puede hablarse de inconsciente racial, en el que determinadas fuerzas pueden cristalizar en un símbolo (como el Mesías en el pueblo judío) que se encarne y produzca un progreso en el conjunto de la humanidad ${ }^{26}$. Vemos cómo una y otra vez Larrea repite una misma visión organicista, armónica y homogénea de la realidad, sea cual sea la dimensión que aborde.

${ }^{24}$ Cf. $M$, p. 146: "Quiere todo lo anterior decir que por ahora más me inclino a creer en la existencia de un inconsciente efectivo del género humano o de la raza blanca por lo menos, que en la de inconscientes diversos y parciales. Estos más bien pueden considerarse como estados de espíritu fruto del desenvolvimiento del inconsciente general tan vasto y complejo. Si la psicología individual presenta tal variedad enorme de tipos de apariencia contradictoria, de combinaciones, de crisis, hemos de pensar que el pleno conocimiento de la psicología genérica habría de maravillarnos con sus inesperadas y complejísimas transmutaciones".

25 J. Larrea, Orbe, p. 40.

26 La raza judía es "el aparato genésico del psiquismo de la humanidad" ( $M$, p. 146); en este sentido, es la raza reprimida, como es reprimida la cuestión sexual, sostiene Larrea. Es importante observar cómo (dentro de su concepción monista) la relación entre los pueblos reproduce la relación entre consciente e inconsciente. La raza blanca reprime a la judía, como el consciente al inconsciente. 
Varios sucesos de su vida llevan a Larrea a estar convencido de la existencia de un Hado o Destino que va a dirigir no sólo al individuo, sino a todos los hombres hacia el cumplimiento de un plan prefijado. En Orbe se manifiesta en los famosos "casos" (presentimientos, sueños premonitorios, episodios extraños) ${ }^{27}$. Asistimos a una personalización de este subconsciente (que se convierte en principio rector que parece saber hacia dónde se dirigen todas las acciones; se trata de una fuerza inconsciente para el hombre, pero consciente para sí, de modo que se asemeja a lo divino, al ser el motor que desarrolla la vida, quedando ignoto para el hombre):

Pero cabe preguntarse ¿no existe otra clase de instintos? Y lo digo refiriéndome a mi experiencia personal, a ese aspecto de providencialismo que a cierta luz presenta la vida humana. Lo que pudiera llamarse Hado, Destino, que cuando no es sino el resultado o descomposición de ciertas causas lanzadas con anterioridad, aparece como perfectamente razonable; pero que cuando se presenta sabiendo y dirigiendo el individuo hacia un fin no previsto, como tendencia hacia una organización nos deja perplejos y sin saber cómo interpretar. A veces parece presumible que una fuerza, inconsciente para el individuo, pero que actúa en su interior, no es inconsciente para ella misma. Por eso el individuo sin saber, guiado únicamente por su oscuro gusto, obra atraído por un diferente aspecto de las cosas. Pero en otras circunstancias no es fácil imaginar que esa fuerza opere exclusivamente en su interior, puesto que los actos no sólo dependen de él, sino asimismo de otras personas. En este caso sólo es aceptable suponer que una fuerza inconsciente para todos ellos ha desviado su acción conjunta hacia un determinado punto. ¿El inconsciente de la masa, de una entidad superior? La providencia que ven actuar a posteriori los místicos religiosos, ¿puede interpretarse de otro diferente modo? (En ciertos momentos se dijera que el destino del mundo está supeditado a vuestro destino). Admitido el inconsciente objetivo de una colectividad, ¿qué colectividad es esa que rige nuestra vida? ¿Es la de una sociedad, de una nación, la de una religión, la de una raza o la de la humanidad? En último término, la voluntad cósmica a la que la tierra obedece, ¿no podría asimismo manifestar su influjo sobre el individuo? Lo cierto es que, sea ella cualesquiera, esa voluntad superior existe y que se manifiesta en los actos de los individuos sin que éstos hayan tenido la

27 Cf. Bary, op. cit., p. 70. Sobre los "casos" de Orbe, cf. B. Del Pliego, op. cit., pp. 152-155. 
menor consciencia de su dirección. Y ¿cómo ha podido dirigir la acción del individuo sin que éste se dé cuenta y sin que su voluntad proteste? Por la inconsciencia; porque este individuo ha sido llevado al acto por otras apariencias apetecibles de dicha acción; por su inconsciente como en los casos de olvido; es decir operando sobre el individuo como un oscuro instinto.

Entonces, los instintos esenciales no desviados ¿no serían más que la manifestación del anhelo de una entidad superior? No es imposible. No es imposible que seamos consecuencia del dolor (¿) de la tierra desgarrada por fuerzas contrarias. Arrancarse el dolor, arrojarlo fuera de sí, confiarlo a otra especie de ser, quizá sea éste el dinamismo del universo. El hombre como la célula tiende a la formación de un ente más grande, buscando su tranquilidad personal e infundiendo al ser creado el desequilibrio causa de su sufrimiento ( $M$, pp. 143-145).

La extensión de la cita anterior se justifica al encontrarnos ante un texto crucial en el pensamiento larreano. Se observa en el texto citado cómo la tendencia inconsciente es un impulso "hacia una organización" 28 , es decir, una tendencia organicista que lleva a desplegar de manera inexorable (y a pesar de todos los afanes, las intenciones, las acciones de los hombres involucrados en los hechos) los propósitos que conducen a un nivel más complejo de la realidad, a la formación de un ente superior. El hombre, por tanto, queda despojado de libertad e independencia, es movido por la fuerza inconsciente universal por medio de su inconsciente. Por otra parte, el tejido orgánico que conforman los colectivos humanos se revela al preguntarse Larrea por la colectividad que rige la vida de los hombres: sociedad, nación, religión, raza, humanidad ${ }^{29}$. El desarrollo de lo inconsciente en su brotar describe cada vez círculos más amplios que se imbrican con los estratos anteriores, conformando un conjunto altamente complejo. El origen de este impulso pa-

28 El instinto natural hacia la organización es estudiado por von Hartmann a través de múltiples ejemplos animales (el más tópico, el de las abejas).

29 Era esta una creencia difundida en la época. Cf. Psicología de las masas y análisis del yo: "Cada individuo forma parte de varias masas... Participa así de muchas almas colectivas: la de su raza, su clase social, su comunidad confesional, su estado, etc., y puede, además, elevarse hasta cierto grado de originalidad e independencia" (S. Freud, op. cit., p. 2600). En El "yo" y el "ello", Freud enlaza con Groddeck para mostrar esta concepción de un yo pasivo, que en vez de vivir "es vivido" por poderes ignotos e invencibles (ibid., p. 2706). 
rece encontrarse, como se observa tanto en este texto como en otros de Orbe, en una voluntad cósmica. Sea cual sea el nombre que se le dé, como queda claro en el texto, Larrea no admite dudas sobre la existencia de este impulso que rige toda la realidad, y fuera del cual no queda absolutamente nada. Se distingue de la fuerza ciega de Schopenhauer, pues "sabe" (quizá de un modo no pleno), acercándose (en este rasgo pro-vidente) al Inconsciente de Hartmann: realmente esta fuerza en origen une lo consciente y lo inconsciente, es super-cons-inconsciente (como veremos al final), recibiendo rasgos de lo divino. Así puede desplegarse en consciencia e inconsciencia, generando lo múltiple de modo orgánico hasta constituir una realidad compleja superior y un modo de conocimiento más pleno o desarrollado a través del hombre. De nuevo, el símbolo organicista de la semilla que genera el árbol podría iluminar este despliegue ya contenido (aunque no realizado) en el principio. Mientras en Schopenhauer la voluntad carece de fin último en todos sus fenómenos ${ }^{30}$, la teleología preside el pensamiento de Larrea.

En el origen encontramos nuevamente la batalla entre fuerzas contrarias como principio de la vida, el movimiento como fruto del dolor de una tierra "desgarrada por fuerzas contrarias". La idea de que el dinamismo del universo procede del deseo de arrancarse el dolor vuelve a conectar con la filosofía de Hartmann $^{31}$, al igual que la unión de la fuerza teleológica inconsciente y los instintos ${ }^{32}$. En el fondo, intuimos la cosmovisión de Schopenhauer, que con tanta fuerza impregnó la literatura española finisecular: el dolor forma la esencia de la vida. No obstante, es simultánea en Orbe esta búsqueda de ausencia de dolor (que pasará más adelante a denominarse "salud", empleando un concepto más acorde con las bioideologías de la época y de un modo especial con el pensamiento nietzscheano) con otro propósito de estirpe idealista: la conquista de un elevado conscien-

30 A. Schopenhauer, op. cit., p. 239.

31 Eduard von Hartmann, Philosophy of unconscious, Trübner \& Co., Ludgate Hill, London, 1893, t. 2, p. 365. En el origen del movimiento de la vida (en la Uni-totalidad) no se encuentra una idea o representación, sino en el dolor (E. von Hartmann, op. cit., t. 2, pp. 257-258). Esta concepción de un Dios sufriente sometido al devenir es heredera de Schelling.

32 A ello dedica von Hartmann gran parte del primer volumen de la Filosofía de lo inconsciente (de manera específica, el capítulo tercero de la primera parte dedicada a lo inconsciente en la naturaleza) y el capítulo primero de la segunda parte de este volumen (dedicado a los instintos en la mente humana). 
te (en el que salga a la luz lo inconsciente) ${ }^{33}$. En este sentido, la Naturaleza se va a servir del yo para que el consciente cumpla su fin $(M$, p. 68), engañándolo, ya que pensando que trabaja para sí, trabaja para otro de quien es simple instrumento, pues "la finalidad del hombre no es el hombre mismo, como la del martillo no es un martillo" ( $M$, p. 130). El hombre no es fin, sino medio en este despliegue inexorable de la fuerza inconsciente.

El hombre queda subordinado a una entidad anterior en el tiempo, la entidad "telúrica" 34 , debiendo identificarse con este "ente psíquico telúrico" en un proceso que no puede dejar de recordar la individuación (identificación con el Sí-Mismo) jungiana ${ }^{35}$. De hecho, algunos individuos "nacidos bajo ciertos signos" (obsérvese el lenguaje determinista procedente de la astrología) representan la encarnación del inconsciente genérico. El ejemplo principal es Cristo (uno de los símbolos del Sí-Mismo en Jung). Estas encarnaciones muestran el determinismo absoluto que emana de la concepción larreana: el contacto con la realidad no los modifica, viven enclaustrados "en

33 O la "conquista del consciente de la tierra" (J. LARrea, Orbe, p. 26). En Hartmann se encuentra, dada su estirpe idealista, este "incremento de la conciencia" como meta del reino animal y toda su organización (MANUEL Pérez Cornejo, "Estudio preliminar", en Filosofía de lo bello: una reflexión sobre lo inconsciente en el arte, de Eduard von Hartmann, Universitat de València, València, 2001, p. 24); esta voluntad oscura e inconsciente que pugna por hacerse consciente y luminosa procede de Schelling (Eusebi Colomer, El pensamiento alemán de Kant a Heidegger, Editorial Herder, Bercelona, 1995, t. 2, p. 116).

34 El sometimiento del individuo a esta fuerza "telúrica" (término de un fuerte componente biologicista) revela la cercanía (en el maremágnum de corrientes herederas del idealismo alemán y de Nietzsche que se produce en esta época) a tendencias ideológicas que ensalzan el determinismo vinculado a la tierra

35 Si bien esta doctrina jungiana puede rastrearse en Gotthilf Heinrich von Schubert, quien distinguía tres partes constitutivas del ser humano, concibiéndolas en constante "devenir". La vida humana suponía una serie de metamorfosis; en ocasiones ocurría una repentinamente poco antes de la muerte, o una vez superada la mitad de la vida (recuérdese la crisis de edad de la que habla Larrea en Orbe). Así, el hombre se encuentra dotado de un segundo centro, la Selbstbewusstsein, que emerge gradualmente en su alma (Henri F. Ellenberger, El descubrimiento del inconsciente. Historia y evolución de la psiquiatría dinámica, Gredos, Madrid, 1970, p. 242). También encontramos un antecedente en Troxler, quien concibe el curso de la vida humana como una serie de metamorfosis psíquicas, siendo el centro de la personalidad no el yo en sentido ordinario, sino lo que denomina "Gemüt" o "Ich selbst" (Ellenberger, op. cit., p. 824). 
un mundo interior de coordenadas colectivas" ( $M$, p. 147), pues son el instrumento de uno de los aspectos del inconsciente que tiende a plasmarse. Estos hombres son definidos como arquetipos que contienen "la fuerza de individualización" (obsérvese la terminología jungiana). Estos casos extremos ponen de relieve la concepción del hombre en Larrea, fruto de una fuerza anónima que va conduciendo de manera directa los destinos de todo lo existente, llegando a encarnarse en momentos de la historia para provocar determinados cambios en la evolución. Esta fuerza encarnada se dirige a un fin que no puede dejar de lograr.

El individuo corriente no es una cristalización semejante, pero "en su desenvolvimiento revive como el embrión todos los estados anteriores de la humanidad hasta llegar al estado actual" ( $M$, pp. 147-148). Esta recapitulación puede quedar confinada en el inconsciente o, en casos extraordinarios (ésta sería la experiencia del propio Larrea), puede llegar al consciente. La tarea del hombre superior será precisamente la de traer a la conciencia todo lo que permanece oculto. Larrea adapta en este caso la teoría de la recapitulación, que sostiene que el desarrollo embrionario de cada especie (ontogenia) repite completamente la historia evolutiva de dicha especie (filogenia). Cada uno de los estadios que el individuo de una especie atraviesa en su desarrollo embrionario representa una de las formas que apareció en su historia evolutiva. La teoría de la recapitulación de Haeckel, que Larrea acepta para el embrión, parece aplicarla al individuo y la vincula al inconsciente, como si en éste se encontrase toda la historia de la humanidad. En cada hombre, pues, se halla todo el pasado de la especie, toda la herencia de la Naturaleza (vemos de nuevo la fuerte solidaridad y trabazón de todo lo existente).

Carl Gustav Carus había defendido que en el período embrionario se desarrolla el inconsciente formativo que después del nacimiento continúa dirigiendo el crecimiento del individuo y la función de sus órganos. La conciencia surge de forma gradual, pero permanece siempre bajo la influencia del inconsciente, al que el individuo retorna periódicamente durante el sueño y mediante el cual se une con el conjunto de los hombres (ibid., pp. 242-245); Jung defiende igualmente que en la vida psicológica la ontogénesis corresponde a la filogénesis ${ }^{36}$ :

36 Carl Gustav Jung, Símbolos de transformación, Ediciones Paidós, Barcelona, 1993, p. 48. 
la vida psíquica del niño y el sueño repiten anteriores etapas del desarrollo. Citando a Nietzsche ("Durmiendo y en sueños rehacemos toda la tarea de la humanidad primitiva") observa cómo el espíritu lleva siempre las huellas de la evolución recorrida y revive en los sueños y las fantasías las épocas más distantes. Observamos, por tanto, cómo en Larrea confluye toda la rica tradición romántica del inconsciente que llega al siglo xx. Ésta va a ser la fuerza o impulso orgánico que despliega lo existente, conduciéndolo hacia su fin.

Larrea emplea los elementos freudianos (al igual que hace, aunque en menor medida, con la psicología de Janet) en una concepción idealista más amplia. La armonización de estos materiales no es extraña pues, como señala Henri F. Ellenberger ${ }^{37}$, si las enseñanzas de Jung son incomprensibles sin la filosofía de Schelling, los conceptos freudianos sobre la vida mental, dominados por polaridades (dualismo de instintos, polaridades sujeto-objeto, placer-displacer, activo-pasivo) conectan igualmente con el pensamiento idealista. Asimismo, las semejanzas entre las enseñanzas de Freud y Schopenhauer han sido mostradas por Thomas Mann o Max Scheller: Mann observó cómo la descripción del ello y del yo era muy cercana a la contraposición entre voluntad e intelecto de Schopenhauer, trasladada de la metafísica a la psicología ${ }^{38}$. Como observamos, estos conceptos freudianos se integran en una visión metafísica que concibe el inconsciente de un modo distinto al freudiano. La creencia en un inconsciente colectivo parece estar más cerca de la concepción jungiana ${ }^{39}$; por otra parte, si bien acepta la existencia de dos instintos básicos que se oponen, en otros textos menciona la existencia de más instintos. Igualmente, la idea de progreso es opuesta a la cosmovisión freudiana y es básica en la concepción larreana (los instintos esenciales no son más que "la ma-

37 C.G. Jung, op. cit., p. 240.

38 H.R. Ellenberger, op. cit., pp. 246-247.

39 En "Instinto e inconsciente" (publicado en 1919) ya conceptualiza Jung lo inconsciente colectivo, incluyendo en él tanto los instintos como los arquetipos de la intuición (C.G. JuNG, La dinámica de lo inconsciente, Trotta, Madrid, 2004, p. 134). Larrea menciona la tesis del "subconsciente colectivo" de la escuela jungiana (Juan Larrea, Razón de ser, Cuadernos Americanos, México, 1956, p. 150), uniéndolo a las teorías antropológicas del "superpsiquismo inconsciente propio de las culturas" que condiciona la vida de los individuos. Las raíces de esta concepción del subconsciente son fácilmente rastreables en la filosofía alemana: Schelling, Gotthilf Heinrich von Schubert, Ignaz Paul Vital Troxler, Carl Gustav Carus (fuente de von Hartmann). 
nifestación del anhelo de una entidad superior"); finalmente, que el inconsciente sea una fuerza rectora que conduce a todos los hombres de manera concertada hacia su fin (una fuerza, por tanto, con características propias de lo divino) es absolutamente contrario a Freud. Esta visión de lo inconsciente remite (como venimos señalando) a la filosofía de Eduard von Hartmann y al Idealismo.

\section{VOLUNTAD UNIVERSAL COMO FUERZA INCONSCIENTE TELEOLÓGICA}

Lo inconsciente se vincula estrechamente (como en la Filosofía de lo inconsciente) a la Voluntad. Por detrás del hombre existe una Voluntad soberana que lo utiliza como instrumento:

Partiendo de la hipótesis de que todo tiene un objeto, en vez de preguntarnos: qué es el hombre, deberíamos investigar: para qué sirve el hombre. Como todo cuanto existe, aunque en su resonancia interna se oigan los gritos de una lucha, no es una lucha, sino el instrumento de una lucha. Vedle situado en los límites de la consciencia y de la inconsciencia con un pie en cada orilla pudiendo transformar en voluntad consciente la voluntad soberana que rige el mundo. Esta voluntad soberana es cuanto a nosotros inconsciente. Hay cosas que no puede mandar porque las ignora, pero sin darnos cuenta nos produce una necesidad y los medios para cubrirla, un dolor y los medios de encontrar alivio. Para algo sirve esta necesidad, este dolor, etc. ( $M$, p. 42).

La concepción de una Voluntad inconsciente procede, como es sabido, de Schopenhauer. Como afirma en El mundo como voluntad y representación, la Voluntad se muestra como "un ciego afán, un sordo y oscuro impulso", fuerza de tendencia inconsciente que no puede ser reconocida inmediatamente ${ }^{40}$. En efecto, la terminología del párrafo es de fuerte sabor schopenhaueriano-hartmanniano. En primer lugar, el mundo es el campo de batalla de una lucha encarnizada. Según Schopenhauer, la Voluntad se desdobla en dos acciones cualitativamente distintas y contrarias que tienden a combinarse de nuevo y se manifiestan casi siempre por una divergencia de direcciones opuestas. De la lucha de los fenómenos inferiores resulta el fe-

40 A. Schopenhauer, op. cit., p. 240. 
nómeno superior que los absorbe a todos y que realiza su aspiración hacia un estado más alto. La Naturaleza se despliega así mediante una batalla continua entre fuerzas que aspiran a conquistar la materia; de ahí que por toda parte se descubran conflictos y peleas (ibid., pp. 237-239).

El hombre no es el protagonista de esta batalla, sino un simple instrumento engañado: desde esta filosofía, el hombre ha dejado de ser un fin en sí mismo (en clara negación de la ética kantiana), ha perdido su lugar en el cosmos y, desgajado ya de la teología cristiana (según la cual era la cúspide de la creación al ser imagen de Dios) se convierte en un peón de una batalla que le trasciende y por la que se encuentra determinado.

Igualmente, se observa en el texto anterior de Orbe una oposición entre consciencia e inconsciencia que recuerda a la pareja Voluntad-Representación; la Voluntad es inconsciente para el hombre, pero éste se encuentra sometido a ella; en el hombre la Voluntad puede llegar a la plena conciencia de sí, reconociendo clara y completamente su propia esencia, de manera que el impulso ciego e inconsciente que originaba la Naturaleza toma en el hombre conciencia de sí (ibid., pp. 382-383); como en Schopenhauer, la tensión que producen la necesidad y el dolor (que nos envuelve en una nueva polaridad -necesidad, satisfacción, nueva necesidad-que encierra al hombre en un círculo vicioso) se descubre como el motor de la acción humana ${ }^{41}$. En el libro cuarto de El mundo como voluntad y representación se desarrolla esta concepción de la naturaleza como constante aspiración sin fin ni descanso, semejante a una sed que nada puede calmar. La base de este querer es la falta de algo y por tanto (sostiene Schopenhauer) el dolor. Hay, sin embargo, un progreso o ascenso evolucionista que tiñe de optimismo el pensamiento larreano, marcado (frente a la falta de finalidad de la voluntad de Schopenhauer) por la teleología. Este esquema no es ajeno al idealismo (uno de cuyos pilares constitutivos es la teleología), como se comprueba claramente en Hegel. Probablemente proceda del influjo que las utopías que triunfan ideológicamente en estos años ejercen sobre el pensamiento (y que contrastan con el pesimismo finisecular). El regreso de la aspi-

41 No obstante, esta concepción sombría del origen sin fondo como deseo, necesidad y voluntad (que sitúa la Voluntad -una voluntad oscura e inconsciente-como raíz de la existencia) procede nuevamente de Schelling y conecta con Jacob Boehme (E. Colomer, op. cit., p. 116). 
ración utópica (y en algunos casos apocalíptica) del período de entreguerras puede incidir sobre un esquema evolucionista que encuentra un antecedente en el ámbito de la filosofía de Schopenhauer en la metafísica de von Hartmann. Igualmente influyen tanto corrientes vitalistas (en especial, Bergson) como el pensamiento de Nietzsche.

El concepto de voluntad que se descubre en Orbe también produce la ruina de la unidad de la persona. Por una parte, en el estado de desagregación del yo que la crisis produce, se revelan en el interior del individuo múltiples voluntades que combaten entre sí, pues a todo lo que es capaz de individualización es inherente esta fuerza de la voluntad: voluntad cósmica, colectiva, individual (con dos subvoluntades: sexual y somática); la voluntad que dirige al individuo será producto del equilibrio de ellas ${ }^{42}$. Por otra parte, la voluntad individual está sometida (siendo un simple instrumento) a una fuerza ajena; que le aparezca a la conciencia como subordinada es un simple engaño en aras de su mejor funcionamiento. Este engaño es, por tanto, necesario (todo hecho es necesario en la realidad, por ello, todo lo real es bueno), así como la renuncia a la voluntad (tentación en la que cae Larrea en su proceso espiritual) es otro engaño que el hombre debe superar ${ }^{43}$. Este engaño que supera es, por consiguiente, la ética de Schopenhauer (coronación práctica de su sistema), que ha de ser trascendida: tanto la piedad como la renuncia a la voluntad son rechazadas en Orbe.

En todo caso, el hombre pierde su libertad y autonomía para ser conducido por fuerzas ajenas que no puede controlar: "no hay voluntad sino conformidad a las leyes mecánicas" ( $M, \mathrm{p}$. 131). Obra inconsciente lo que otra voluntad le manda, guiándolo como a un niño, mediante engaño ( $M$, p. 127). Así sucede en la filosofía de Schopenhauer: éste afirma que todo fenómeno es absolutamente necesario, y se encuentra determinado necesaria e inmutablemente en el encadenamiento de causas y efectos. En la Naturaleza se observa claramente, pues en ella el conjunto de sus fenómenos es absolutamente imprescindible, pudiéndose demostrar la necesidad de cada parte. Schopenhauer aplica también esta necesidad a cada acto de la conduc-

${ }^{42}$ No puede dejar de recordar la interpretación que de Leibniz hace von Hartmann en el capítulo sexto del segundo volumen de Philosophy of the unconscious: "The conception of individuality".

${ }^{43}$ Cf. $M$, p. 172. Por tanto "es preciso ser engañado para desengañarse". 
ta humana ${ }^{44}$ y Larrea traslada esta condición al conjunto de la realidad, de modo que los acontecimientos pueden ser intuidos, previstos. La realidad funciona orgánicamente, como en la Naturaleza, o como en el arte: al igual que cada fragmento de una obra es requerido por el conjunto; así, cada elemento de la realidad está necesariamente previsto de cara a la totalidad de la obra. La diferencia se encuentra (como en toda la filosofía idealista) en el paso que se da en la conciencia humana: en la reflexión y en el arte, este impulso inconsciente se torna consciente. En este sentido, el hombre aparece como el instrumento mediante el cual la Voluntad desplegada (y no totalmente consciente) toma posesión de sí misma, llegando de este modo a plenitud.

La crisis lleva a Larrea a descubrir la existencia de un lenguaje universal que se encuentra en contradicción con la voluntad de los hombres, pero que actúa en ellos inconscientemente, encauzando el destino, imponiéndolo con "la fuerza ineluctable de los hechos consumados" ( $M$, p. 316). El hombre es "un instrumento ciego manejado por una voluntad perteneciente a su subconsciente que no tenía relación alguna con sensación de yo" ( $M$, p. 252). Por ello, el antiguo individuo ha de ser triturado, reducido a sus más mínimos componentes para que el subconsciente pueda manejarlo con el menor daño. Se encamina, por tanto, hacia un punto en el que el dolor sea suprimido del mundo ( $M$, p. 317): "Cuando esté en plena posesión de mi destino el dolor será ausente de mi vida. Pero para eso será preciso que mi voluntad esté de tal modo regulada, que esté en perfecto acuerdo con la acción venidera" ${ }^{45}$. El hombre ha de ajustarse al progreso, al devenir del mundo; esta regulación de la voluntad, que se somete al destino fijado por la Voluntad, lo libera del dolor. Abandona, pues, aquí, la filosofía de Schopenhauer de un modo bastante claro. Según éste, el hombre había de renunciar de una manera perfecta a toda voluntad, negándola y suprimiéndola, con el fin de librarse del mundo y precipitarse en el abismo de la nada. Pero en Larrea se pretende negar la voluntad individual para acordarla con la Voluntad primordial, cuyo designio ha de favorecer. Este cambio implica también una conversión en la valoración ética de este impulso: en Schopenhauer es considerada una pulsión negativa que es ne-

44 A. Schopenhauer, op. cit., pp. 381-382.

45 Así lo afirma en una nota del 24 de octubre de 1931. 
cesario abolir de un modo definitivo; en Larrea, en cambio, es un principio positivo. Concuerda, pues, en este caso con otras filosofías idealistas (Schelling o Hegel).

Larrea interpreta el proceso de crecimiento que experimenta a lo largo de la crisis como la muerte de su individualidad para renacer como yo plural, tras dejar atrás la prisión que suponían la conciencia, la voluntad y la memoria, que estallan al descubrir la Voluntad (el Ser) que obra en su interior:

Y esas cosas que quiero que ocurran, puesto que suceden, si están en desacuerdo con mi sensación de voluntad, es porque existe una inadaptación entre el ser y sus atributos. La sensación de voluntad que poseo, es decir, que poseía, no estaba en relación con la calidad del ser que obraba en mí. Mi consciencia era estrecha y por tanto mi voluntad, mi memoria, mi inteligencia y demás atributos y potencia interiores. La historia del mundo, desde que existe recuerdo, no es sino el proceso de adaptación del ser a las condiciones relativas del mundo de los sentidos. Salido el hombre de un estado de vital inconsciencia, tiende a otro estado parecido, al que sólo se puede llegar a través de la experiencia consciente y como tal dolorosa de la pluralidad. Una vez que la unidad ha sido deshecha, su nueva formación sólo es factible por la pluralidad total. Aquí está el símbolo hebreo del paraíso, cuyo acceso al oriente sólo podrá lograrse por una nueva unidad. Y mientras esa unidad plural no haya sido realizada, la lucha intestina, el desasosiego desacordado, la incomprensión, el dolor de los componentes del yo, tanto individual como universal, tendrán razón de ser en la inexistencia del ser ( $M$, pp. 343-344)

La crisis se convierte en crisis universal, un doloroso parto de lo viviente hasta que todo el organismo se adapte. Si el autor ya ha vivido este trastorno y nuevo nacimiento, la existencia de otros hombres que viven en el error crea tensiones entre lo viejo y lo nuevo que no encontrarán su fin sino hasta la constitución del nuevo organismo, tras "la completa eliminación de las depresiones ideológicas y biológicas causantes de la agudeza de la crisis" ( $M$, p. 346). Consecuentemente, si cuanto sucede es fruto de una Voluntad inconsciente que rige y dirige el mundo, el bien será lo que "es", el mal lo que no es: "Bueno lo que existe, ha existido o existirá; malo lo que no existe, no ha existido y no existirá" ( $M$, p. 149). Cualquier hecho, por ser fruto de este despliegue del germen originario, es lo bueno (ha de ser así), aunque parezca negativo, ya que, incluso el 
peor mal viene a funcionar como instrumento para que el proyecto de la Voluntad llegue a su término. Se llega a la paradoja de postular conveniente la ignorancia del hombre, que le hace creer que sabe, fortaleciendo así su sensación de voluntad (individual). Aunque esta ignorancia frena la evolución, evita un paso en falso que redundaría en un perjuicio mayor. En un sentido (hegeliano) similar interpreta Hartmann la frase de Leibniz (el mundo que existe es el mejor de los mundos posibles) ${ }^{46}$. Una concepción semejante del progreso en la Historia podemos hallarla en el capítulo 10 de la segunda parte de su Filosofía de lo inconsciente ("The unconscious in History") ${ }^{47}$. En palabras de Hartmann, ciertos males son inevitables a pesar de ser inapropiados para ciertos fines, porque evitarlos sería inapropiado para más importantes fines. Así, "en la sed de riquezas, de comodidades y bienes materiales, en el orgullo y vanidad de los hombres, tan denigrados por los espiritualistas, parece sin embargo descansar hoy día una gran parte de la eficiencia de la necesidad de desarrollo evolutivo" ${ }^{4}$. En este punto queda patente y manifiesto el esquema fuertemente idealista de la filosofía de Larrea y hasta qué punto se produce una transvaloración de los conceptos de Schopenhauer ${ }^{49}$.

${ }^{46}$ Cf. cap. 12 del t. 2, "The supreme wisdom of the unconscious and the perfection of the world".

47 "But the wonderful part of the matter is, that even the mind, which wills the bad, works the good, that the results become, by combination of many different selfish purposes, quite other than what each individual had imagined, and that in the last resort they always conduce to the welfare of the whole, although often the advantage is somewhat remote, and centuries, retrogression seems to contradict it; this contradiction, however, is only apparent, for they serve the purpose of breaking the strength of an old system, that room may be made for a new and better one, or of allowing a vegetation to grow corrupt, in order that it may manure the ground for something fresh and fairer. Even thousands of years of stagnation on one spot of earth should not mislead us, if only at the same time the process of evolution goes forward at another place" (E. von HARTMANn, op. cit., t. 2, pp. 2-3).

48 J. LaRrea, Orbe, p. 105.

49 Cf. Max Scheler, De lo eterno en el hombre, Ediciones Encuentro, Madrid, 2007, p. 46: "Sólo Nietzsche y Bergson se atrevieron, ante aquello mismo que ya Schopenhauer había vivido y contemplado como su fundamento del mundo -aquel poder impulsivo, codicioso, demoníaco, que levanta formas de existencia nuevas y cada vez más abigarradas-, no a deplorarlo de un modo pesimista, a sufrirlo resignadamente o a huirlo ascéticamente como Schopenhauer, sino a afirmarlo, a regocijarse y a exigir del hombre que se lance enteramente a ese poder, de cabeza, como a una rápida corriente. Para eso, naturalmente, tenía que alterarse de un modo fundamental el 
De este modo se explica la amoralidad que continuamente aparece en Orbe: defendiendo la selección natural, considera que la piedad es absurda y no se debe prolongar la vida de un ser defectuoso ( $M$, p. 74); la moral es relativa (el Bien y el Mal absolutos no existen; cf. "Amoralismo", $M$, p. 148), por lo que no hay hombres mejores ni peores ( $M$, p. 118); influido por Nietzsche, defiende la crueldad y la indiferencia, idéntica a la del yo colectivo, desalmado para el hombre ( $M$, p. 185). En Philosophy of the unconscious sostiene Hartmann que la moralidad y la justicia sólo tienen importancia desde el punto de vista de la individuación, es decir, pertenecen sólo al mundo de la apariencia, no a su esencia ${ }^{50}$. Vemos nuevamente cómo uno de los principios fundamentales de la filosofía schopenhaueriana (el principal de su ética), la piedad, queda abolido por la pulsión idealista de esta filosofía (cercana en estos puntos a la hegeliana) y el pathos nietzscheano que impregna estos años Europa.

De esta concepción determinista (el fin se encuentra en su germen) procede la importancia concedida al instinto: "Creo que en todo hombre sano existe como animal un instinto, es decir, una fuerza inconsciente que le hace escoger, cuando el cerebro no se lo impide, lo mejor. Este instinto radica en los nervios" $(M, \text { p. } 41)^{51}$. La importancia de los instintos había sido subrayada por Schopenhauer, para quien la Voluntad era una fuerza ciega que, en los niveles más bajos de la Naturaleza, actúa con total seguridad e infalibilidad. Pero con el advenimiento de la razón aparece la vacilación, la incertidumbre, y el error se hace posible. Esta filosofía de lo instintivo fue desarrollada por Eduard von Hartmann. En los instintos (observa Hartmann) no hay indecisión, duda o fluctuación de la voluntad, ni error alguno (como sucede en la voluntad consciente ${ }^{52}$ ); esta clarividencia (Hellsehen) se manifiesta en las premoniciones, presentimientos de muerte, corazonadas, sonambulismo, etc. ${ }^{53}$. Las corazo-

sistema de valores; por tanto, negarse por principio toda moral cristiana, como igualmente toda moral humanitaria”.

50 E. von Hartmann, op. cit., t. 2, p. 364.

${ }^{51}$ W. James (Principles of Psychology II) define el instinto como "a mere excito-motor impulse, due to the preexistence of a certain «reflex-arc» in the nerve-centres" (citado por C.G. JuNG, La dinámica de lo inconsciente, pp. 131-132).

${ }^{52}$ E. von Hartmann, op. cit., t. 2, p. 98.

53 Ibid., t. 1, p. 108. 
nadas constituyen uno de los motivos fundamentales de Orbe $e^{54}$, pues, dice Larrea, el inconsciente "sabe" (lo inconsciente de Hartmann es conocimiento y sabiduría plenos). De ahí que en el texto "Profecías" ( $M$, p. 212) declare su convencimiento de que en el futuro el hombre será capaz de predecir el porvenir.

\section{IMAGINACIÓN}

A fines de 1931 (período en el que se cumple la crisis y concluye el presente trabajo) comienza a cobrar importancia en Orbe el concepto de Imaginación. Así se observa en un texto inédito (fundamental en el desarrollo del posterior pensamiento de Larrea) fechado el 6 de noviembre de 1931, que lleva por título, precisamente "Imaginación". La voluntad se reduce ahora a la individualidad y la consciencia, y la Imaginación aparece como "potencia equivalente dentro del hombre actual a la Idea de Dios, la que se imagina a sí misma, la que no es atributo sino verbo" (M 355-356), de ahí que, como ha señalado Helena López González de Orduña, "se trata de una categoría que remite a los términos judeocristianos de Principio de Creación, Logos y Verbo y que supone una voluntad ajena al individuo que se expresa a través de la palabra profética" 55 . La Imaginación no es consciente ni inconsciente, sino "super-cons-inconsciente" (como sería lo inconsciente de Hartmann, cuyos momentos de clarividencia, o superconsciencia, se asemejan a los que describe Larrea precisamente en esta etapa ${ }^{56}$ ). Al mismo tiempo, esta imagen

54 Recuérdese, por ejemplo, la apuesta por el caballo "Baccarat".

55 Vanguardia y exilio. Sus representaciones en el ensayo de Juan Larrea, tesis doctoral, Universidad de A Coruña, 2001, p. 50.

56 Cf. el capítulo "The unconscious and the God of theism", en E. von Hartmann, op. cit., t. 2, pp. 246-247: "But we know from the previous inquiries that the function of this unconscious intelligence is anything but blind, rather far-seeing, nay, even clairvoyant, although this seeing can never be aware of its own vision, but only of the world, and without the mirrors of the individual consciousnesses can also not see the seeing eye. Of this unconscious clairvoyant intelligence we have come to perceive that in its infallible purposive activity, embracing out of time all ends and means in one, and always including all necessary data within its ken, it infinitely transcends the halting, stilted gait of the discursive reflection of consciousness, ever limited to a single point, dependent on sense-perception, memory, and inspirations of the Unconscious. We shall thus be compelled to designate this intelligence, which is superior to all consciousness, at once unconscious 
de lo divino no estaría segregada de las fuerzas infernales (así sucede en la línea de pensamiento alemán que conecta a Böhme con Jung), adquiriendo de este modo los caracteres de divinidad que hasta ahora se aplicaban a la Voluntad Inconsciente (y que Eduard von Hartmann atribuye a lo inconsciente). Parece, por tanto, que el Principio originario (mediante despliegue orgánico) de todo lo existente, y con el que el hombre había de identificar su voluntad individual (la Voluntad telúrica o universal), va a recibir un nuevo nombre, Imaginación.

Al mostrarse la imaginación como principal potencia, imagen de la divinidad en el hombre, se fortalece la cosmovisión organicista que ha ido mostrándose en $O r b e^{57}$, enlazando de nuevo con la filosofía de Schelling, quien encuentra en la imaginación "el órgano general de la filosofía y la piedra-clave de su arco", pues unifica lo consciente y lo inconsciente ${ }^{58}$. Pero esta facultad no opera principalmente en la creación literaria, sino en la vida, a la que Larrea aplica la idea de organismo, uniendo (al igual que Coleridge en su concepto de imaginación) mecanismo y teleología ${ }^{59}$. Esto explica el fin de la escritura poética en Larrea, para quien la vida (y la Historia) -en un gesto plenamente vanguardista- se han convertido en la gran obra poética que hay que comprender y llevar a cabo $^{60}$. El organicismo larreano no impide la continua aparición de metáforas mecanicistas, pues tanto unas imágenes como otras apuntan en la misma dirección: la existencia de unas leyes inexorables que controlan toda la vida (también la humana) y conducen a un fin predeter-

and super-conscious... If the latter possesses a superconscious intelligence, all-knowing and all-wise, with all its unconsciousness, which teleologically determines the content of creation and of the world-process, we stand here neither as accidental product of the forces of Nature, nor is God dwarfed by denying Him this mode of consciousness".

57 Sobre la importancia del organicismo en la teoría de la imaginación, cf. M.H. Abrams, El espejo y la lámpara, Barral Editores, Barcelona, 1975, pp. 298 ss. Sobre la imaginación en Orbe, cf. B. Del Pliego, op. cit., p. 138.

58 M.H. Abrams, op. cit., p. 370.

${ }_{59}$ Ibid., p. 298. Díaz de Guereñu remonta la concepción de la imaginación de Larrea (que se opone a la fantasía y a la razón) a sus lecturas de Poe (quien la recibe de Coleridge), cf. Juan Manuel Díaz De Guereñu, La poesía de Juan Larrea. Creación y sentido, Cuadernos Universitarios, San Sebastián, 1988, pp. 60-61.

60 Sobre esta integración de arte y praxis vital como uno de los principales postulados de la vanguardia, cf. PETER Bürger, Teoría de la vanguardia, Ediciones Península, Barcelona, 1995, p. 103. 
minado (aunque desconocido para el hombre) ${ }^{61}$. La cosmovisión de Larrea se enraíza por tanto en la corriente heredera de la Naturphilosophie de Schelling, cimentándose en sus dos ideas primordiales: polaridad y teleología ${ }^{62}$. El modelo artístico, que supera al modelo natural como forma de comprensión de la totalidad de la vida, se convierte en el organon de una filosofía marcada por la organicidad.

\section{Conalusión}

En el presente artículo se ha tratado de mostrar cómo la crisis del yo provoca en Orbe el desmoronamiento de toda la metafísica occidental. Bajo el yo se ha descubierto un impulso único organizador de toda la realidad (previo al individuo e independiente de él) que, mediante la polaridad (identidad en la duplicidad o duplicidad en la identidad), lleva lo existente a un fin concebido con anterioridad por esta fuerza. Este impulso recibe varios nombres (Inconsciente, Voluntad, Imaginación). $\mathrm{Si}$, según hemos visto, la configuración de esta Voluntad se asemeja a la de la filosofía de Schopenhauer, se concibe, en cambio, como un impulso positivo, siendo la fuente de realidad y de valoración; en consecuencia, no sólo no ha de negarse, sino que el fin del individuo habrá de ser negar su voluntad individual para acordarse plenamente a esta Voluntad universal. Esta transformación cierra el proceso de divinización de este Principio que informa y dirige lo existente. El último nombre otorgado a éste, Imaginación, une Naturaleza y Arte y enraíza aún más claramente al vanguardista Larrea con el Idealismo. La Realidad se muestra como desarrollo inexorable de un germen inconsciente, en cuyo proceso el hombre no es más que un momento que conduce a su fin.

Carlos Peinado Elliot Universidad de Sevilla

61 Sobre las semejanzas de estas concepciones, cf. D. NEGRo, op. cit., p. 315 .

${ }^{62}$ E. Colomer, op. cit., p. 102. 